\title{
Misoprostol v/s Cerviprime Gel for Induction of Labour
}

\author{
Patil $\mathbf{P}^{1}$, Patil $\mathbf{A}^{2}$ \\ ${ }^{1}$ Dr.Pooja Patil, Assistant Professor, Department of Obstetrics \& Gynecology, L N Medical College, Bhopal, ${ }^{2}$ Dr.Abhijit Patil, \\ Assistant Professor, Department of Radiodiagnosis, Gandhi Medical College, Bhopal, India
}

Address of correspondence: Dr. Pooja Patil, E-mail: pooja_gynec@yahoo.co.in

\begin{abstract}
Objective: This prospective study was conducted to compare the effect, efficacy \& safety of intra-vaginal misoprostol (PGE 1) \& intra-cervical dinoprostone gel (PGE 2) for induction of labour. Methods: 100 women aged 16-35 years with single live fetus, cephalic presentation \& term pregnancy, who were admitted for induction of labour were included in this study. 50women received intrvaginal 50 microgram Misoprostol(study group) \& 50 women received $0.5 \mathrm{mg}$ of intracervical dinoprostone gel(control group). Comparison was done between the mean time taken for onset of labour, time taken for induction to delivery, mean duration of labour, requirement of Oxytocin augmentation, mode of delivery, side effects $\&$ the neonatal outcome in either of the groups. Results: The mean time taken for onset of labour was less in the misoprostol group than in the dinoprostone group (43.22 min v/s $1 \mathrm{hr} 40 \mathrm{~min}$ ). Similarly duration from induction to active phase (1hr $42 \mathrm{~min}$ v/s $4 \mathrm{hrs} 10 \mathrm{~min}$ )and active phase to delivery ( $3 \mathrm{hrs} 06 \mathrm{~min} \mathrm{v/s} 4 \mathrm{hrs} 54 \mathrm{~min}$ ) was less for misoprostol group and thus the induction to delivery interval (5 hrs $02 \mathrm{~min} \mathrm{v/s} 11 \mathrm{hrs} 12 \mathrm{~min}$ ). None of the study group patients required Oxytocin augmentation. Cesarean section rate was less in misoprostol group ( $6 \% \mathrm{v} / \mathrm{s} 22 \%)$. Maternal side effects were minimal in either group \& the neonatal outcome was good in both the groups. The induction cost was much less in the misoprostol group. Conclusion: Misoprostol is safe, efficacious, cheap and mother and fetus friendly drug for the induction of labour.
\end{abstract}

Keywords: Dinoprostone gel, induction of labour, Misoprostol.

\section{Introduction}

Labor induction is a method of artificially or prematurely stimulating childbirth in a woman ${ }^{1}$. In some $5-25 \%$ of pregnancies, there comes a time when the fetus and /or mother would be better off if delivery was conduccted ${ }^{2}$

Prostaglandins alter the extracellular ground substance of the cervix, ripens the cervix and also increases the activity of collagenase in the cervix. They also allow for an increase in intracellular calcium levels, causing contraction of myometrial muscle ${ }^{(3,4)}$. The FDA revised its labeling for misoprostol in April 2002 from "contraindicated in pregnancy" to "contraindicated in pregnancy for the treatment and prevention of NSAID-induced ulcers." ${ }^{5}$ Currently, two prostaglandin analogs are available for the purpose of cervical ripening -Misoprostol and Dinoprostone gel.

Manuscript received: $11^{\text {th }}$ May 2013

Reviewed: $16^{\text {th }}$ May 2013

Author Corrected; $29^{\text {th }}$ May2013

Accepted for Publication: $20^{\text {th }}$ June 2013
Misoprostol (15-deoxy-16-hydroxy-16 methyl-PGE1) was the first synthetic prostaglandin analogue to be made available for the treatment of peptic ulcer. Impressed by its stimulant actions on the uterus, Sanchez Ramos in 1993 used it for the management of several obstetric conditions. Misoprostol is available as 50, 100, 200 microgram tablets.

Dinoprostone (PGE) is a synthetic preparation of naturally occurring prostaglandin E2. PGE 2 gel is available in 2.5 $\mathrm{ml}$ syringe for an intracervical application of $0.5 \mathrm{mg}$ of Dinoprostone $^{6}$

\section{Material and Methods}

100 women admitted for induction of labour in our hospital were randomly selected for study. 50 women received 50 microgram intrvaginal misoprostol and another 50 women $0.5 \mathrm{mg}$ of intracervical dinoprostone gel. Misoprostol (50microgm) was kept in the posterior fornix after making 
it wet. Doses were repeated in both the groups, 6 hourly for a maximum of 3 doses, if required.

Inclusion criteria: Singleton pregnancy, cephalic presentation, $>36$ completed weeks gestation confirmed by Ultrasonography

Exclusion criteria: Multiple pregnancies, abnormal presentation, pregnancy $<36$ weeks, previous caesarean section.

Study group: Patients who received Misoprostol for induction of labour.

Control group: Patients who received Dinoprostone gel for induction of labour.

The patient was considered in the active phase when there was cervical dilatation of at least $3-4 \mathrm{~cm}$. Women in labour were cared for, according to current obstetric practices.
When they entered active phase, depending on the pattern of uterine contractility, oxytocin was used for augmentation. If women did not reach active phase within $24 \mathrm{hrs}$ of induction, caesarean section was done for failed induction. No augmentation was done when uterine contractions reached a frequency of 3 in 10 minutes. The primary outcome measure was the interval from start of induction to active phase. Success of induction was defined as entry into active phase within 24 hours of the initial administration of the drug.

Other measures studied were need for oxytocin augmentation, interval from active phase to delivery, mode of delivery, need for caesarean section, and side-effects . The results were represented as mean \& standard deviation $\&$ unpaired $\mathrm{t}$ test was applied to know the statistical significance. Qualitative variables were expressed as percentages. Neonatal outcome was measured according to the Apgar score.

\section{Results}

The baseline data of the study population included maternal age, gravidity and gestational age. They were comparable in the two groups. The mean gestational age was identical i.e. 37 to 42 weeks. $64 \%$ in study group and $68 \%$ in control group were in 37-40 weeks of pregnancy as seen in Table No.1.

Table No.1 Gestational age

\begin{tabular}{|c|c|c|}
\hline Gestational age (in wks) & Misoprostol & Dinoprostone gel \\
\hline $37-40$ & $32(64 \%)$ & $34(68 \%)$ \\
\hline $40.1-42$ & $18(36 \%)$ & $16(32 \%)$ \\
\hline
\end{tabular}

Table No.2 Indications for induction

\begin{tabular}{|c|c|c|}
\hline Indication & Misoprostol & Dinoprostone \\
\hline Post date Pregnancy & $18(36 \%)$ & $16(32 \%)$ \\
\hline IUGR & $14(28 \%)$ & $11(22 \%)$ \\
\hline PIH/Pre-eclampsia & $17(34 \%)$ & $20(40 \%)$ \\
\hline Eclampsia & $1(2 \%)$ & $3(6 \%)$ \\
\hline
\end{tabular}

The indications of induction were similar in either groups as mentioned in table No.2. Majority of patients were induced due to post dated pregnancy. Other indications were Intrauterine Growth Restriction, Pregnancy induced Hypertension, Preeclampsia and Eclampsia. 
Table No.3 Mean time taken for onset of labour

\begin{tabular}{|l|l|l|l|l|l|l|l|}
\hline & Misoprostol & Dinoprostone & $\begin{array}{l}\text { Mean } \\
\text { difference }\end{array}$ & $\begin{array}{l}\text { S.D. } \\
\text { (mean) }\end{array}$ & $\begin{array}{l}\text { Standard } \\
\text { error } \\
\text { (mean) }\end{array}$ & t \\
\hline In all patients & $43.22 \mathrm{~min}$ & $1 \mathrm{hr} 40 \mathrm{~min}$ & $56.78 \mathrm{~min}$ & 77.85 & 11.12 & -3.3907 & 0.00069 \\
\hline In Primigravida & $44.37 \mathrm{~min}$ & 1 hour $26 \mathrm{~min}$ & $41.63 \mathrm{~min}$ & 61.69 & 19.00 & -2.0822 & 0.21983 \\
\hline In Multigravida & $43.25 \mathrm{~min}$ & $\begin{array}{l}1 \text { hour } 35.67 \\
\text { min }\end{array}$ & $52.42 \mathrm{~min}$ & 82.12 & 13.96 & -2.7527 & 0.00527 \\
& & & & & \\
\hline
\end{tabular}

The mean time taken for onset of labour was significantly less $(\mathrm{P}=.00069)$ in the misoprostol group $(43.22 \mathrm{~min} \mathrm{v} / \mathrm{s} 1 \mathrm{hour} 40$ $\mathrm{min}$ ) as shown in table No.3.Thus Misoprostol leads to early labour and thus early delivery as compared to the Dinoprostone.

Table No. 4 Induction-delivery intervals

\begin{tabular}{|c|c|c|c|c|c|c|c|}
\hline & Misoprostol & Dinoprostone & $\begin{array}{c}\text { Mean } \\
\text { difference }\end{array}$ & S.D.(mean) & $\begin{array}{c}\text { Standard } \\
\text { error(mean) }\end{array}$ & P & t \\
\hline $\begin{array}{c}\text { Induction } \\
\text { to active } \\
\text { phase }\end{array}$ & $1 \mathrm{hr} 42 \mathrm{~min}$ & $4 \mathrm{hrs} 10 \mathrm{~min}$ & $\begin{array}{c}2 \mathrm{hrs} 28 \\
\min \end{array}$ & 161.76 & 24.61 & -2.71 & 0.006 \\
\hline $\begin{array}{c}\text { Active } \\
\text { phase to } \\
\text { delivery }\end{array}$ & $3 \mathrm{hrs} 06 \mathrm{~min}$ & $4 \mathrm{hrs} 54 \mathrm{~min}$ & $1 \mathrm{hr} 48 \mathrm{~min}$ & 147.10 & 22.33 & -2.599 & 0.01275 \\
\hline $\begin{array}{c}\text { Induction } \\
\text { to delivery }\end{array}$ & $5 \mathrm{hrs} 2 \mathrm{~min}$ & $11 \mathrm{hrs} 12 \mathrm{~min}$ & $6 \mathrm{hrs} 10$ & 377.60 & 54.97 & -3.8077 & 0.0004 \\
\hline
\end{tabular}

In Misoprost group the time taken for induction to active phase ( $1 \mathrm{hr} 42 \mathrm{~min}$ v/s $4 \mathrm{hrs} 10 \mathrm{~min}$ ) was less which is statistically significant as $\mathrm{P}=0.006$. Similarly active phase to delivery interval ( $3 \mathrm{hrs} 06 \mathrm{~min} \mathrm{v} / \mathrm{s} 4 \mathrm{hrs} 54 \mathrm{~min}$ ), was also less and was statistically significant with $\mathrm{P}=0.01$. Overall there is less induction to delivery interval $(5 \mathrm{hrs} 2 \mathrm{~min} \mathrm{v} / \mathrm{s} 11 \mathrm{hrs} 12 \mathrm{~min})$ and this was statistically significant. 
Table No. 5 Mean duration of labour

\begin{tabular}{|c|c|c|c|c|c|c|c|}
\hline & Misoprostol & Dinoprostone & $\begin{array}{c}\text { Mean } \\
\text { difference }\end{array}$ & $\begin{array}{c}\text { S.D. } \\
\text { (mean) }\end{array}$ & $\begin{array}{c}\text { Standard } \\
\text { error } \\
\text { (mean) }\end{array}$ & $\mathbf{t}$ & $\mathbf{P}$ \\
\hline $\begin{array}{c}\text { Duration of } \\
\text { labour(mean) }\end{array}$ & $4 \mathrm{hrs} 22 \mathrm{~min}$ & $7 \mathrm{hrs} 36 \mathrm{~min}$ & $3 \mathrm{hrs} 14 \mathrm{~min}$ & 212.61 & 32.5 & -2.293 & $\begin{array}{c}0.0151 \\
9\end{array}$ \\
\hline $\begin{array}{l}\text { Duration of labour } \\
\text { in Primi (mean) }\end{array}$ & $3 \mathrm{hrs} 10 \mathrm{~min}$ & $7 \mathrm{hrs} 15 \mathrm{~min}$ & $4 \mathrm{hrs} 5 \mathrm{~min}$ & 169.18 & 48.30 & -2.872 & $\begin{array}{c}0.0225 \\
2\end{array}$ \\
\hline $\begin{array}{l}\text { Duration of labour } \\
\text { in multi (mean) }\end{array}$ & $4 \mathrm{hrs} 53 \mathrm{~min}$ & $7 \mathrm{hrs} 51 \mathrm{~min}$ & $2 \mathrm{hrs} 58 \mathrm{~min}$ & 276.13 & 53.39 & -1.501 & $\begin{array}{c}0.1043 \\
2\end{array}$ \\
\hline
\end{tabular}

Mean duration of labour was much less in the misoprostol group ( $4 \mathrm{hrs} 22 \mathrm{~min} \mathrm{v} / \mathrm{s} 7 \mathrm{hrs} 36 \mathrm{~min}$ ) which is significantly less $(\mathrm{P}=0.015)$ as seen in Table No. 5 .Even in Primigravida patients Misoprostol resulted in shorter duration of labour as compared to dinoprostone gel ( $3 \mathrm{hrs} 10 \mathrm{~min} \mathrm{v} / \mathrm{s} 7 \mathrm{hrs} 15 \mathrm{~min}$ ) which is statistically significant as $\mathrm{P}=0.02$

Table No. 6 Oxytocin augmentation

\begin{tabular}{|c|c|c|}
\hline & Misoprostol & Dinoprostone Gel \\
\hline & $\%$ of patients & $\%$ ofpatients \\
\hline Oxytocin augmentation & - & $6 \%$ \\
\hline
\end{tabular}

Oxytocin augmentation was not required in misoprostol group whereas in $6 \%$ cases of dinoprostone group required augmentation as seen in Table No. 6 .

Table no.7 Mode of delivery

\begin{tabular}{|c|c|c|c|c|}
\hline Type of delivery & \multicolumn{2}{|c|}{ No. Of patients } & \multicolumn{2}{c|}{$\%$ of patients } \\
\hline & Misoprostol & Dinoprostone & Misoprostole & $72 \%$ \\
\hline Normal vaginal & 45 & 36 & $90 \%$ & $6 \%$ \\
\hline Instrumental delivery & 2 & 3 & $4 \%$ & $22 \%$ \\
\hline
\end{tabular}

$90 \%$ of patients in misoprost group delivered normally as compared to $72 \%$ in dinoprost group as seen in Table No.7 .Thus less rate of Cesarean section seen in the study group. 
Table No. 8 Indication for Cesarean section

\begin{tabular}{|c|c|c|}
\hline Indication for LSCS & Misoprostol & Dinoprostone \\
\hline Failure of Induction & $1(33 \%)$ & $6(54.55 \%)$ \\
\hline Meconium stained liquor & $2(67 \%)$ & $2(18.18 \%)$ \\
\hline Fetal Distress & - & $11(100 \%)$ \\
\hline Total & $3(100 \%)$ & $(27.27)$ \\
\hline
\end{tabular}

Only 1 patient in study group had failure of induction whereas in control group 6 patients had failure of induction. The main indication of Cesarean section in control group was failure of induction as mentioned in Table No. 8. In the study group, Cesarean section was done mainly for meconium stained liquor which was also the second major indication for Cesarean section in the control group.

Table No. 9 Side effects

\begin{tabular}{|c|c|c|}
\hline SIDE EFFECTS & \%OF PATIENTS & Dinoprostone \\
\hline & Misoprostole & $4 \%$ \\
\hline Nausea, Vomiting & $8 \%$ & $4 \%$ \\
\hline Fever with chills & $16 \%$ & - \\
\hline GI symptoms & $6 \%$ & $6 \%$ \\
\hline Hyperstimulation & $8 \%$ & $12 \%$ \\
\hline
\end{tabular}

Although maternal complications like fever with chills, Hyperstimulation (Hypersystole \& tachysystole) \& Meconium stained liquor were more in misoprostol group than in dinoprostone group as shown in Table No. 9. Significant side effect were not encountered.

Table No. 10 Neonatal outcome

\begin{tabular}{|c|c|c|}
\hline APGAR SCORE $<$ 7 & Misoprostole & Dinoprostone \\
\hline After 1 min & - & $6 \%$ \\
\hline After 5 min & - & $4 \%$ \\
\hline Need for NICU & - & $4 \%$ \\
\hline
\end{tabular}

Apgar score $<7$ was seen in 3 cases of dinoprostone group out of which 2 have been admitted in NICU. None of the newborn in the study group had Apgar score $<7$.

The mean overall induction cost in Misoprostol group was much less in contrast to the high overall induction cost in dinoprostone group. 


\section{Discussion}

The introduction of Prostaglandins to clinical practice, particularly their local use for cervical ripening, has decreased major difficulties of labour induction. Duration between induction and delivery has been decreased dramatically by introduction of Prostaglandins. Similarly it also decreased associated complication of amnionitis and fetal infection

The baseline data of our study population including maternal age, gravidity and gestational age were comparable with similarstudies $7,8,9$

In our study, indication for induction in Misoprostol group were post date pregnancy in $36 \%$ and Pre-eclampsia in 34\% whereas in Dinoprostone group 32\% and 40\% respectively induced for postdated pregnancy and Pre-eclampsia. Thus majority of indication was due to these two conditions. Post dated pregnancy was the main indication for induction in other studies ${ }^{7,8,9}$.

The mean time taken for onset of labour was less in misoprost group (43.22 $\mathrm{min} \mathrm{v/s} 1 \mathrm{hr} 40 \mathrm{~min}$ ). There was no significant difference between the primigravida and the multigravida in both the groups regarding the time taken for onset of labour.

In this study the mean induction to delivery interval was less in the misoprost group ( $5 \mathrm{hrs} 02 \mathrm{~min} \mathrm{v} / \mathrm{s} 11 \mathrm{hrs} 12 \mathrm{~min}$ ), which is statistically significant $(\mathrm{P}=<.001)$. Similar results were seen in study in 2003 by Agarwal et al ${ }^{10}$ where it was $12.8+/-6.4 \mathrm{hrs}$ v/s $18.53+/-8.5$ hours. In 2003 D.Garry et $\mathrm{al}^{11}$ also concluded in his study that interval from start of induction to vaginal delivery was significantly shorter in the misoprostol group.

Also in another study of Murthy Bhaskar Krishnamurthy in 2006, induction delivery interval was shorter in the misoprostol group. Other reported studies ${ }^{12,13}$ also had parallel observation. Thus misoprostol reduces the mean duration of labour which reduces the duration of suffering of a patient in labour and also provides fast delivery which is required in cases of Premature rupture of membranes, eclampsia and fetal distress.

In our study Oxytocin augmentation was not needed in any case in the misoprostol group whereas in Dinoprostone group 3 patients required it. In study by Neiger $R$. Greaves $^{14} 50 \%$ patients in study group required Oxytocin augmentation and $90 \%$ in the control group.
The present study showed that Misoprostol was able to increase the vaginal deliveries compared to the control group as $94 \%$ patients delivered vaginally in study group compared to $78 \%$ in the control group. Thus Misoprostol

had decrease rate of Cesarean section (6\%) compared to Dinoprostone (22\%). This was consistent with the study of Sahu Latika et $\mathrm{al}^{7}(8 \% \mathrm{v} / \mathrm{s} 20 \%)$ and also with the study of Patil Kamal et $\mathrm{al}^{8}$ and Murthy Bhaskar et $\mathrm{al}^{9}$.

In the present study, in the study group, out of 3 patients who underwent cesarean section only one was for failure of induction whereas in the control group 6 out of 11 patients operated for Cesarean section due to failure of induction. Thus the main indication of Cesarean section in the dinoprostone group was failure of induction which was consistent with the study by Patil Kamal et $\mathrm{al}^{8}$ and Murthy Bhaskar et $\mathrm{al}^{9}$.

In the Misoprostol group 2 out of 3 patients underwent Cesarean section due to meconium stained liquor though in the Dinoprostone group 3 patients had Cesarean section due to meconium stained liqour. Though in the misoprostol group, total 6 patients had meconium stained liquor compared to 3 patients in the Dinoprostone group. Thus meconium stained liqour was seen more in the study group.

Maternal side effects were minimal in both the groups. In Misoprost group, $16 \%$ patients had fever with chills, $8 \%$ had nausea and vomiting and 6\% had GI symptoms, $8 \%$ had hyperstimulation. Hypertonus was defined as one contraction with a duration of $>2$ minutes, tachysystole as $>6$ contractions in 10 minutes for two consecutive 10 minute periods ${ }^{15}$.

Uterine hyperstimulation is when either of these condition(hypertonus or tachysystole) leads to a non reassuring fetal heart rate pattern ${ }^{16}$.Because of the frequency of tachysystole with vaginal administration of misoprostol, some researchers are studying oral and sublingual/buccal routes to determine if effectiveness can be maintained while decreasing the incidence of tachysystole. ${ }^{16-18}$.

In 2000, G.D.Scarle \& Company notified physicians that misoprostol is not approved for labour induction or abortion. Despite this American College of Obstetricians \& Gynecologists(2000) quickly reaffirmed its recommendation for use of the drug because of proven safety \& efficacy ${ }^{16}$ 
The neonatal outcome in both the groups was comparable. Birth weights were similar in both the groups. Apgar score $<7$ at 1 min was seen in 3 cases of Dinoprostone group out of which two had to be admitted to NICU. Sahu Latika et al also had $12 \%$ newborns with Apgar $<7$ at one minute in the dinoprostone group which is consistent with our study.

The mean overall induction cost in Misoprostol group was much less in contrast to misoprostone group. As Misoprostol does not need refrigeration, its affordability as well as its availability in the peripheral areas is more than the Dinoprostone gel which requires refrigeration.

\section{Conclusion}

Our study results revealed that, Misoprostol is better inducing agent as compared to the Dinoprostone gel because it has short induction to delivery intervals and thus short duration of labour and advantage of rapid labour as required in cases of pre-eclampsia and eclampsia .

The need of Oxytocin augmentation was less with the Misoprostol and it results in more vaginal deliveries compared to Dinoprostone. Thus Misoprostol reduces the Cesarean section rate and also has less chances of failure of induction.

Although hyperstimulation and meconium stained liquor was more in Misoprost group in few patients and did not had any effect on the neonatal outcome. Misoprostol also does not need cold chain storage and is cheaper. Thus Misoprostol can be considered as safe, efficacious, cheap and mother and fetus friendly drug for the induction of labour.

\section{Conflict of interest: None}

\section{Permission from IRB: Yes}

\section{References}

1. Houghton Mifflin Company, The American Heritage Dictionary, 2006

2. Beischer NA, Mackay EV, Colditz PB. Obstetrics and the Newborn, An Illustrated Textbook 1997,3:449

3.Witter FR . Prostaglandin E2 preparations for preinduction cervical ripening. Clin Obstet Gynecol. 2000;43:469-74.
4. Arias F. Pharmacology of oxytocin and prostaglandins. Clin Obstet Gynecol 2000;43:455 68 .

5. American College of Obstetricians and Gynecologists. New U.S. Food and Drug Administration labeling on Cytotec (Misoprostol) use and pregnancy. Committee Opinion Washington, DC: American College of Obstetricians and Gynecologists; 1999;. 283

6. F.Gary Cunningham, Kenneth J.Leveno, Steven L.Bloom, John C., Rouse,Spong, Williams Obstetrics,2010;23:502

7. Sahu Latika,et al. Comparison of Prostaglandin

E1(Misoprostol) with Prostaglandin E2(Dinoprostone) for Labor Induction. J Obstet Gynecology India 2004; 54(2):139-142

8. Patil $\mathrm{K} P$ et al. Oral Misoprostol v/s intra-cervical dinoprostone for cervical ripening and labour induction. $J$ Obstet Gynec India 2005; 55(2):128-131

9. Murthy BK et al. Misoprostol alone versus a combination of Dinoprostone and Oxytocin for induction of labour. J Obstet Gynec India 2006;56(5):413-416

10. Agarwal N, Gupta,A, Kriplani ,Bhatla NP. Six hourly vaginal misoprostol versus intracervical Dinoprostone for cervical ripening and labour induction.J Obstet and Gynecology Res 2003;29(3):147-51.

11. Garry D, Figueroa R, Kalish RB. Randomized Controlled Trial of Vaginal Misoprostol Versus Dinoprostone Vaginal Insert for labour induction Journal of Maternal-Fetal and Neonatal Medicine 2003; $13(4): 254-259$

12. Calder AA, Loughney $\mathrm{AD}$,Weir CJ, Barber JW. Induction of labour in nulliparous and multiparous women: a UK, multicentre, open-label sudy of intrvaginal misoprostol in comparison with dinoprostone. BJOG 2008;115(10):1279-88.

13.Sebiha Ozkan, Eray Caliskan, Emek Doger, Izzet Yucesoy, Semih Ozeren, Birol Vural. Comparative safety and efficacy of vaginal Misoprostol versus Dinoprostone Vaginal insert in labour induction at term: a Randomized Trial. Archives of Gynecology and Obstetrics 2009;280(1):19-24 
14. Neiger R. Greaves PC. Comparison between Vaginal Misoprostol and Cervical Dinoprostone for cervical ripening and labour induction. Tenn Med. 2001;94(1):25-7

15. F.Gary Cunningham, Kenneth J.Leveno, Steven L.Bloom, John C., Rouse,Spong. Williams Obstetrics,2010;23:503

16. Cheng SY, Ming H, Lee JC. Titrated oral compared with vaginal misoprostol for labor induction: A randomized controlled trial. Obstet Gynecol. 2008;111:119-125.
17. Muzonzini G, Hofmeyr GJ. Buccal or sublingual misoprostol for cervical ripening and induction of labour. Cochrane Database Syst Rev. 2004;4:CD004221.

18. Colon I, Clawson K, Hunter K, Druzin ML, Taslimi

MM. Prospective randomized clinical trial of inpatient cervical ripening with stepwise oral misoprostol vs vaginal misoprostol. Am J Obstet Gynecol. 2005;192:747-752.

\section{How to cite this article?}

Patil $\mathrm{P}^{1}$, Patil $\mathrm{A}^{2}$. Misoprostol v/s Cerviprime Gel for Induction of Labour. Int J Med Res Rev 2013;1(2):63-70. doi: 10.17511/ijmrr.2013.i02.04 